\title{
Characterization of titanium-hydroxyapatite biocomposites processed by dip coating
}

\author{
R BAPTISTA ${ }^{1,4}$, D GADELHA ${ }^{2}$, M BANDEIRA ${ }^{2}$, D ARTEIRO ${ }^{2}$, M I DELGADO ${ }^{2}$, \\ A C FERRO ${ }^{3,5}$ and M GUEDES ${ }^{1,5, *}$ \\ ${ }^{1}$ Department of Mechanical Engineering, Setúbal School of Technology, Instituto Politécnico de Setúbal, \\ 2910-761 Setúbal, Portugal \\ ${ }^{2}$ Setúbal School of Technology, Instituto Politécnico de Setúbal, 2910-761 Setúbal, Portugal \\ ${ }^{3}$ Department of Mechanical Engineering, Instituto Superior Técnico, Universidade de Lisboa, Av. Rovisco Pais, \\ 1049-001 Lisboa, Portugal \\ ${ }^{4}$ IDMEC, Instituto Superior Técnico, Av. Rovisco Pais, 1049-001 Lisboa, Portugal \\ ${ }^{5}$ CeFEMA, Instituto Superior Técnico, Av. Rovisco Pais, 1049-001 Lisboa, Portugal
}

MS received 18 May 2015; accepted 14 September 2015

\begin{abstract}
Ti orthopaedic implants are commonly coated with hydroxyapatite (HA) to achieve increased biocompatibility and osseointegration with natural bone. In this work the dip-coating technique was used to apply HA films on Ti foil. A gel was used as the support vehicle for commercial HA particles. The experimental parameters like surface roughness of the metallic substrate and immersion time were studied. All coated substrates were heat treated and sintered under vacuum atmosphere. The produced coatings were characterized by field-emission gun scanning electron microscopy coupled with energy-dispersive spectroscopy, X-ray diffraction, Raman spectroscopy, microhardness, scratch test and profilometry. Additionally, the apatite-forming ability of the produced material was tested by exposure to a simulated body fluid. Higher substrate surface roughness and longer immersion time produce thicker, denser films, with higher surface roughness. Lower film porosity is accompanied by higher hardness values. However, thicker coating promotes differential shrinkage and crack formation during sintering. Both coating thickness and coating roughness increase with coating time. HA films $\sim 30-40 \mu \mathrm{m}$ thick with 45-50\% HA theoretical density produced on Ti substrates with surface roughness of $R_{\mathrm{z}} \sim 1.0-1.7 \mu \mathrm{m}$, display an attractive combination of high hardness and resistance to spallation. Attained results are encouraging regarding the possibility of straightforward production of biocompatible and bioactive prosthetic coatings for orthopaedic applications using commercial HA.
\end{abstract}

Keywords. Biocomposites; orthopaedic implants; hydroxyapatite coating; titanium substrate; dip coating.

\section{Introduction}

Hydroxyapatite (HA), $\mathrm{Ca}_{10}\left(\mathrm{PO}_{4}\right)_{6}(\mathrm{OH})_{2}$, is the most used ceramic for applications inside the human body because of its excellent biocompatibility, osteoconductive properties, thermodynamic stability in body fluids, and general compositional similarity with human calcified hard tissues (e.g., bone and teeth) [1-3]. However, its potential to be used as an implant is limited by low tensile strength, low fatigue resistance and elastic modulus mismatch [4], resulting in the usage of HA most often in the form of films deposited upon metallic substrates. In this context, titanium and its alloys have been extensively used as the metallic part of implantable materials due to the combination of significant properties such as high strength and fracture toughness, lightweight and high corrosion resistance. While titanium and its alloys have very good properties for fixation applications and act as the load-bearing part $[5,6]$, coating with HA further contributes to the implant/bone

\footnotetext{
*Author for correspondence (mafalda.guedes@estsetubal.ips.pt)
}

bonding ability and increases fixation stability. HA coating of titanium implants thus combines the mechanical and bioinert properties of a well-established implant metal with the osteoconductive properties of HA [7], and as been associated with improved long-term prostheses performance [8].

Available HA coating techniques include plasma spraying, electrophoretic deposition, sputtering and sol-gel synthesis. Usual drawbacks to these techniques include full or partial HA melting and/or decomposition, difficulty to assure high crystallinity, generation of intermediate calcium phosphate salts other than $\mathrm{HA}$ (most often $\mathrm{CaO}, \alpha$-tricalcium phosphate or $\beta$-tricalcium phosphate) and contamination with reagents. However, the microstructure, range and purity of the calcium phosphate phases produced during the coating process are determinant to the long-term stability, bioactivity and biocompatibility of the coatings $[2,5,7,9]$. Contamination of HA or formation of deficient HA results in significant changes in its morphological and crystallographic features, affecting the quality of the final product. In as much, development of reliable, scalable and fast coating techniques are of great significance to the biomedical community. 
In the current work the sol-gel technique is used for the deposition of crystalline HA films on a metal substrate in order to obtain a composite biomaterial. In the used approach sol-gel is used not as a route to synthesize HA, but rather as a straightforward and inexpensive coating method. A sol is prepared containing added commercial HA particles of wellknown composition. Gelation of this sol renders a stable carrier, enabling the application of uniform coatings by dipping, with precise control over the crystallographic and chemical structure and composition of the HA powder in the sol-gel [10]. The difficulties in preparing a stable coating while synthesizing synthetic HA crystals from aqueous solution are thus expected to be surpassed.

\section{Experimental}

Experiments were carried out with commercially pure titanium (grade 1) foil with $380 \mu \mathrm{m}$ thickness, and commercial HA for REGEN from AGORAMAT.

Ti strips with approximately $20 \mathrm{~mm} \times 20 \mathrm{~mm}$ were prepared by abrasion with $\mathrm{SiC}$ grit paper under distilled water, up to a surface finish of 240, 400, 800 and 1200 mesh. Immediately before gel deposition the strips were sonicated in acetone during $20 \mathrm{~min}$ and blow dried.

The sol-gel method was used to prepare a stable gel, adapting the method reported by Aksakal et al [10]. This gel was further used as a carrier for commercial HA particles with well-known composition and crystalline structure. The commercial HA was first milled by planetary ball milling (PM100, RETSCH) at $400 \mathrm{rpm}$ during $120 \mathrm{~min}(10: 1$ ballto-powder ratio; alumina balls and vial), in the presence of the same weight of ethanol. $\mathrm{P}_{2} \mathrm{O}_{5}$ (47 wt $\%$ of the HA powder weight), $\mathrm{Na}_{2} \mathrm{CO}_{3}$ (20 wt \%), $\mathrm{KH}_{2} \mathrm{PO}_{4}$ (3 wt \%), and glycerol $(1 \mathrm{wt} \%)$ were then added to the mixture, which was further homogenized by milling at $200 \mathrm{rpm}$ during $10 \mathrm{~min}$. Particle size distribution of starting and milled powders was evaluated by laser diffraction (L1064, CILAS). Ti strips were then dip coated in the attained HA carrier gel, with immersion times of 1,5 and $10 \mathrm{~s}$ for all surface finishes. A single HA layer was deposited. After coating samples were kept at room temperature overnight to allow for solvent evaporation, and calcined at $120^{\circ} \mathrm{C}$ during $10 \mathrm{~h}$ for removal of organic material [10]. It followed a sintering step under primary vacuum $(600 \mathrm{mbar})$, with $4^{\circ} \mathrm{C} \mathrm{min}^{-1}$ heating rate up to $750^{\circ} \mathrm{C}$ and holding time of $60 \mathrm{~min}$. Samples were slowly cooled to room temperature under vacuum, inside the furnace to avoid cracking. The low sintering temperature was chosen in order to avoid the $\alpha \rightarrow \beta$ phase transition in Ti (at approximately $885^{\circ} \mathrm{C}$ for pure Ti) [11] and the accompanying significant volume change, while maximizing the HA-Ti tensile bonding strength [10]. The flowchart in figure 1 outlines the experimental procedure used to generate the HA coating.

Surface roughness was evaluated using a profilometer (SJ201P/M, Mitutoyo), both before coating and after coating and sintering. Sintered film thickness was evaluated using the same equipment.

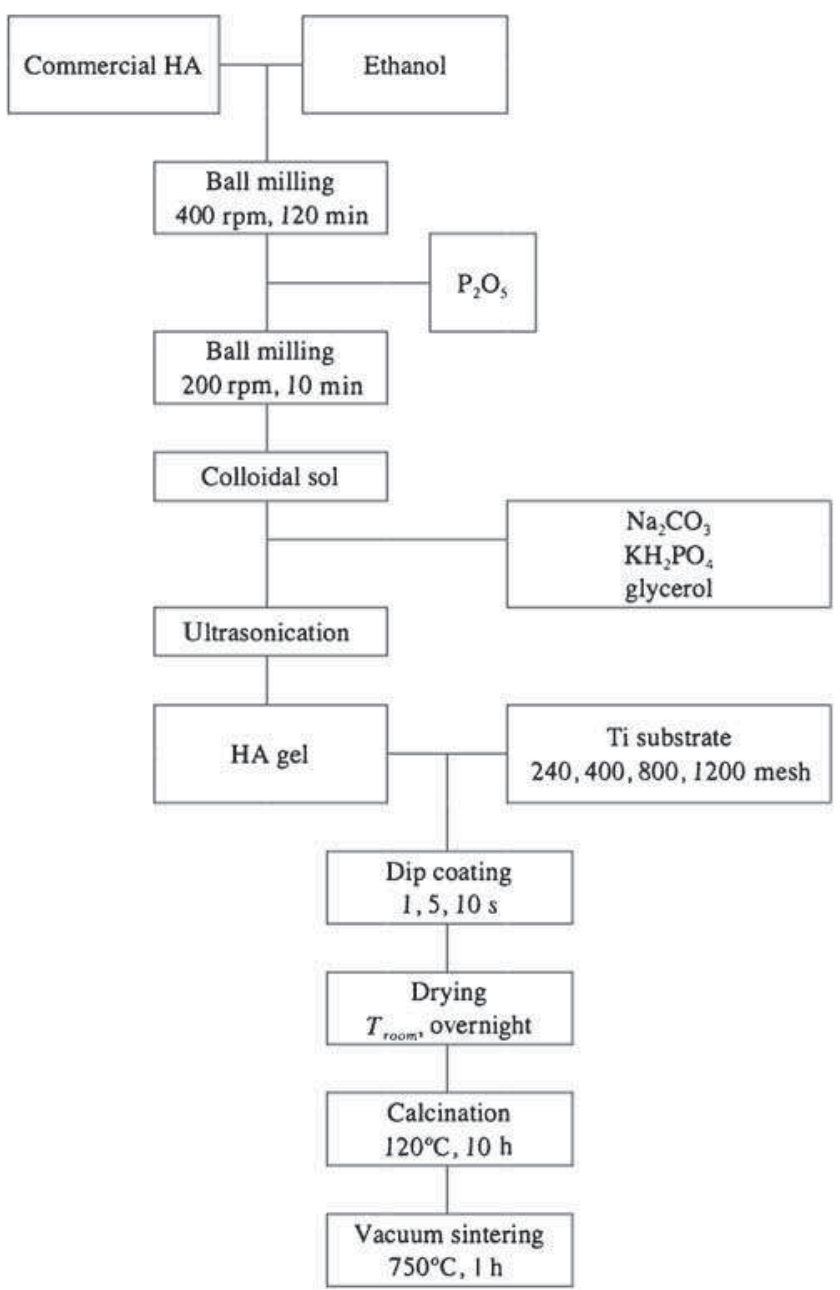

Figure 1. Outline of carrier-gel processing and $\mathrm{Ti}$ coating procedure.

Thermal evolution of the as-prepared gel was monitored by simultaneous differential thermal analysis and thermogravimetry (DTA/TG) (STA 409 PC Luxx, Netzsch). Crystalline phases present after sintering were assessed by X-ray diffraction (XRD) analysis using $\mathrm{CuK}_{\alpha}$ radiation (PW 3020, Philips); samples were scanned in the $2 \theta$ range between $20^{\circ}$ and $60^{\circ}$, with step size of $0.02^{\circ}$ and step time of $2 \mathrm{~s}$.

Raman spectroscopy was used to identify the functional groups on both the Ti substrate surface and on the applied HA layer. Raman spectra of all the samples were collected with a micro-Raman spectrometer (HR Evolution, Horiba JobinYvon), using a $100 \times$ objective lens. A $532 \mathrm{~nm}$ laser was used for excitation of the Raman signal, with 600 grooves $\mathrm{mm}^{-1}$ grating. Five accumulations, with acquisition time of $10 \mathrm{~s}$ were used.

Microstructural observations were carried out using fieldemission gun scanning electron microscopy (FEG-SEM) (JSM-7001F, Jeol), coupled with energy-dispersive spectroscopy (EDS) microanalysis (Inca pentaFETx3, Oxford Instruments).

Coated samples were further characterized concerning the mechanical behaviour of the ceramic films. Vickers hardness 
measurement (1 kgf) was carried out using a standard diamond indenter (M4U-025, EMCO), with indentation duration of $10 \mathrm{~s}$. Coating indentation tolerance was assessed by scratch test (prototype, equipped with Rockwell C indenter). Three scratches were made on each coating using loads of 1,2 and $4 \mathrm{kgf}$. Scratching was undertaken at a sliding speed of $2 \mathrm{~mm} \mathrm{~s}^{-1}$ to a scratch length of $5 \mathrm{~mm}$. Indentation marks and scratch grooves were examined by electron microscopy.

The produced composites were also evaluated regarding the in vitro ability of apatite to form on their surface, by exposure to a simulated body fluid (SBF). Unpolished sintered samples of the produced materials were immersed in SBF ( $\mathrm{pH}$ 7.4) with ion concentrations similar to those of human blood plasma during 4 weeks at $36.5^{\circ} \mathrm{C}$, following the protocol developed by Kokubo et al [12].

\section{Results and discussion}

\subsection{Characterization of starting $\mathrm{HA}$ particles and $\mathrm{Ti}$ substrate}

All peaks in the X-ray pattern of as-supplied HA powder correspond to $\mathrm{Ca}_{10}\left(\mathrm{PO}_{4}\right)_{6}(\mathrm{OH})_{2}$; no foreign crystalline phases were identified within the equipment detection limit. Figure 2a compares particle size and distribution of assupplied and milled HA powders. After milling $d_{50}$ reduces from approximately $1.61-1.49 \mu \mathrm{m}(\sim 7.5 \%)$. While the fine fraction remains roughly unaffected by milling, the coarse fraction is significantly decreased, with $d_{90}$ reduction of approximately 54\%. Milled particles exhibited irregular shape with rounded edges (figure $2 b$ ). EDS elemental analysis did not show the presence of contaminants arising from the milling media.

The titanium surfaces produced by abrasion are homogeneous, with uniformly distributed scratches resulting from grinding (figure 3). Average roughness $R_{\mathrm{z}}$ of the treated metallic surfaces varies between a maximum of approximately $2.29 \mu \mathrm{m}$ for the 240 mesh finish $\left(R_{\mathrm{a}}=0.51 \mu \mathrm{m}\right)$ and a minimum of approximately $0.90 \mu \mathrm{m}$ for the 1200 mesh finish $\left(R_{\mathrm{a}}=0.39 \mu \mathrm{m}\right)$ (figure 4$)$. Figure 5 shows the Raman spectra for uncoated Ti foil as a function of the imposed heat treatment. The as-supplied material exhibits a very shallow band around approximately $830 \mathrm{~cm}^{-1}$, attributed to native amorphous titania [13]. Annealing in air at $120^{\circ} \mathrm{C}$ for $10 \mathrm{~h}$ results in the formation of the rutile phase, as indicated by the bands at 836, 609, 434 (Ti-O) and $241 \mathrm{~cm}^{-1}$ (O-O) [13]. Bands characteristic of amorphous carbon species are present in the foils at $120^{\circ} \mathrm{C}$, as indicated by the characteristic peaks at 1329 and $1583 \mathrm{~cm}^{-1}(\mathrm{C}-\mathrm{C})$ and $1087 \mathrm{~cm}^{-1}$ (C-O) [13]. These species result from the decomposition of organic residues at the surface and are eliminated during further heating up to $750^{\circ} \mathrm{C}$. Also, the crystallinity of the rutile phase increases, as indicated by the relative intensity increase and sharpening of the bands at 241, 445 and $608 \mathrm{~cm}^{-1}$.
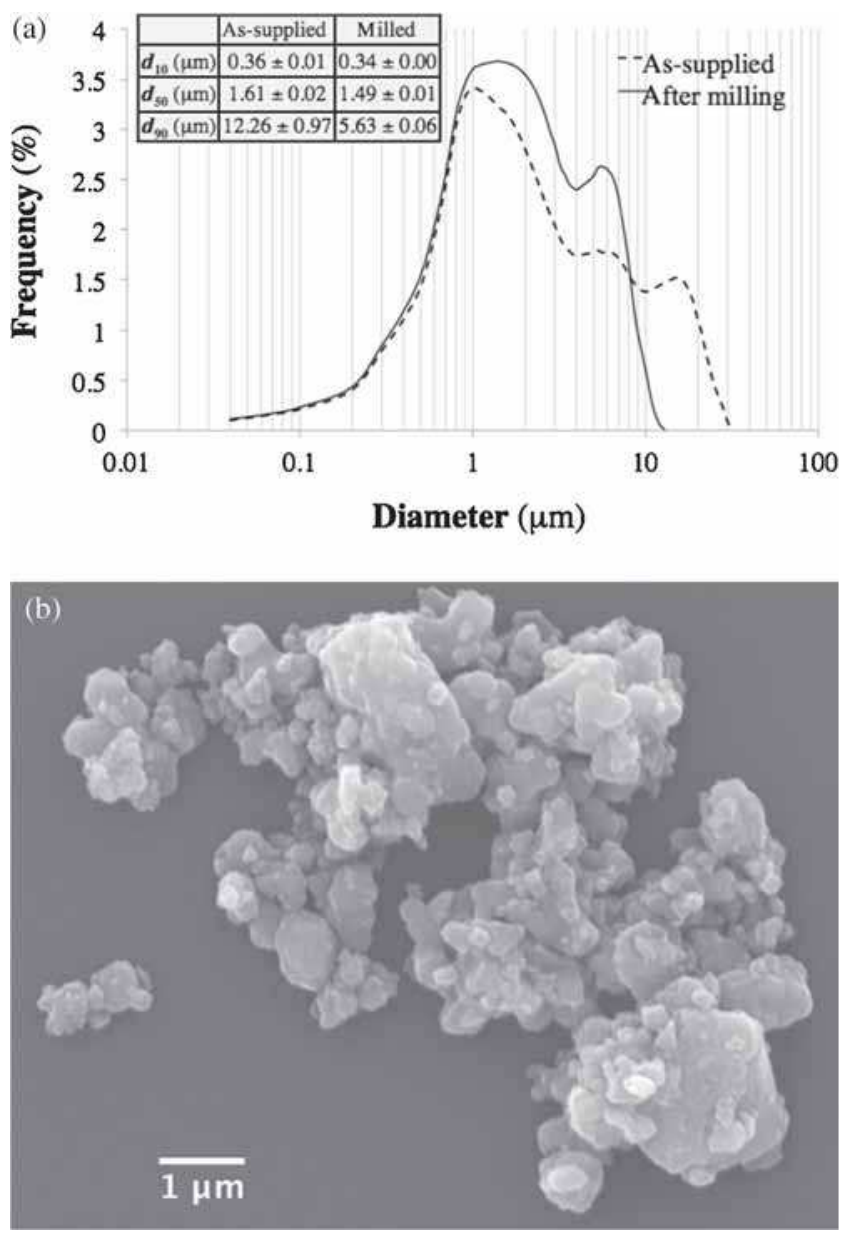

Figure 2. Used commercial hydroxyapatite: (a) particle size distribution of as-supplied (dashed line) and milled HA (full line). Superimposed table summarizes the corresponding cumulative diameters. (b) Secondary electron (SE) image of the HA powder after milling.

\subsection{Characterization of the produced gel}

The milled HA powders yielded homogeneous suspensions, stable against sedimentation. $\mathrm{P}_{2} \mathrm{O}_{5}$ reacts with alcohol to form $\mathrm{P}(\mathrm{O})(\mathrm{OR}) 3$ oxyalkoxide with liberation of water, which in turn hydrolyses the oxyalkoxide [9]. The presence of the formed phosphorus hydroxyl-oxyalkoxide is not itself sufficient to form a gel, but is responsible for further polymerization reaction involving $\mathrm{Na}_{2} \mathrm{CO}_{3}$, which results in the gelation process [9]. $\mathrm{P}_{2} \mathrm{O}_{5}, \mathrm{Na}_{2} \mathrm{CO}_{3}$ and $\mathrm{K}_{2} \mathrm{PO}_{4}$ additionally toil as sintering agents in order to aid densification, and have been suggested to improve the mechanical performance of HA without altering its biocompatibility [1].

The thermal evolution of the prepared gel was monitored by DTA/TG (figure 6). The shape of the TG curve has three distinct regions of mass loss during heating: between room temperature and approximately $180^{\circ} \mathrm{C}(33 \%)$, between 180 and $310^{\circ} \mathrm{C}(22.5 \%)$, and above $310^{\circ} \mathrm{C}$ (the mass loss determined in the $310-760^{\circ} \mathrm{C}$ range was $5.8 \%$ ). The first mass 

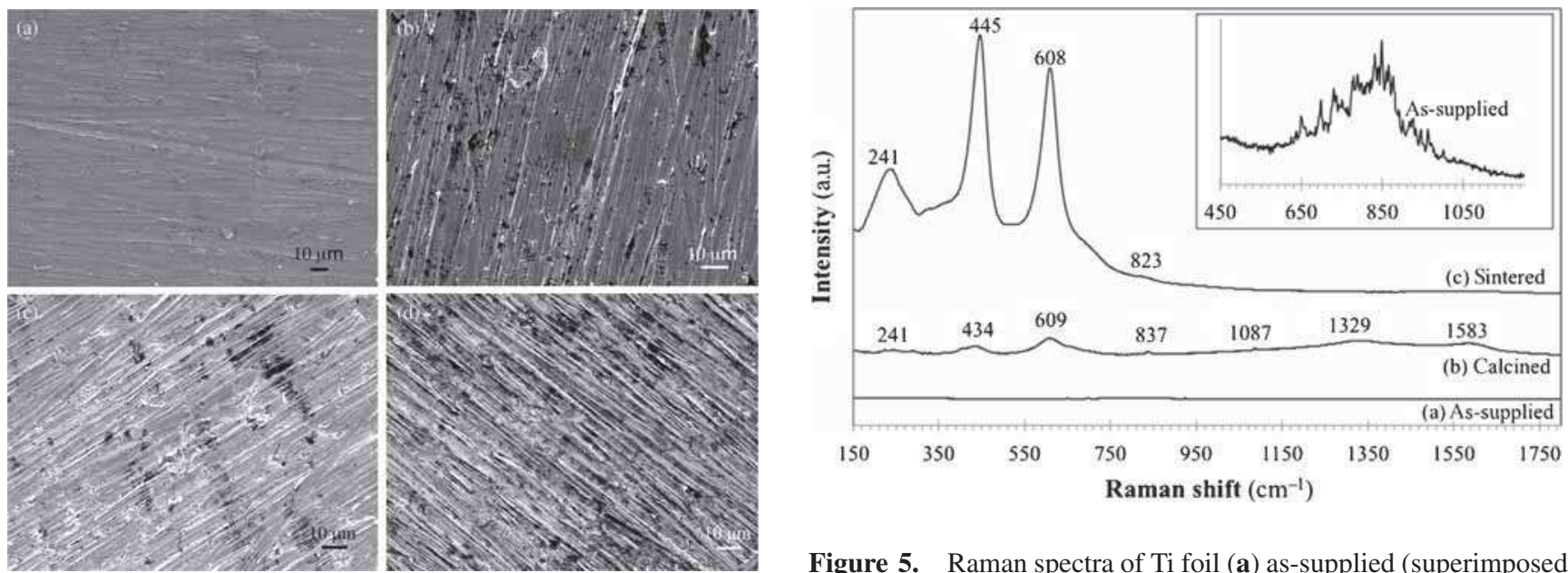

Figure 5. Raman spectra of Ti foil (a) as-supplied (superimposed chart shows spectrum magnification); (b) after calcination at $120^{\circ} \mathrm{C}$

Figure 3. Low-magnification SE image of Ti strips after grinding to different surface finishes: (a) 240 mesh; (b) 400 mesh; (c) 800 mesh; and (d) 1200 mesh.
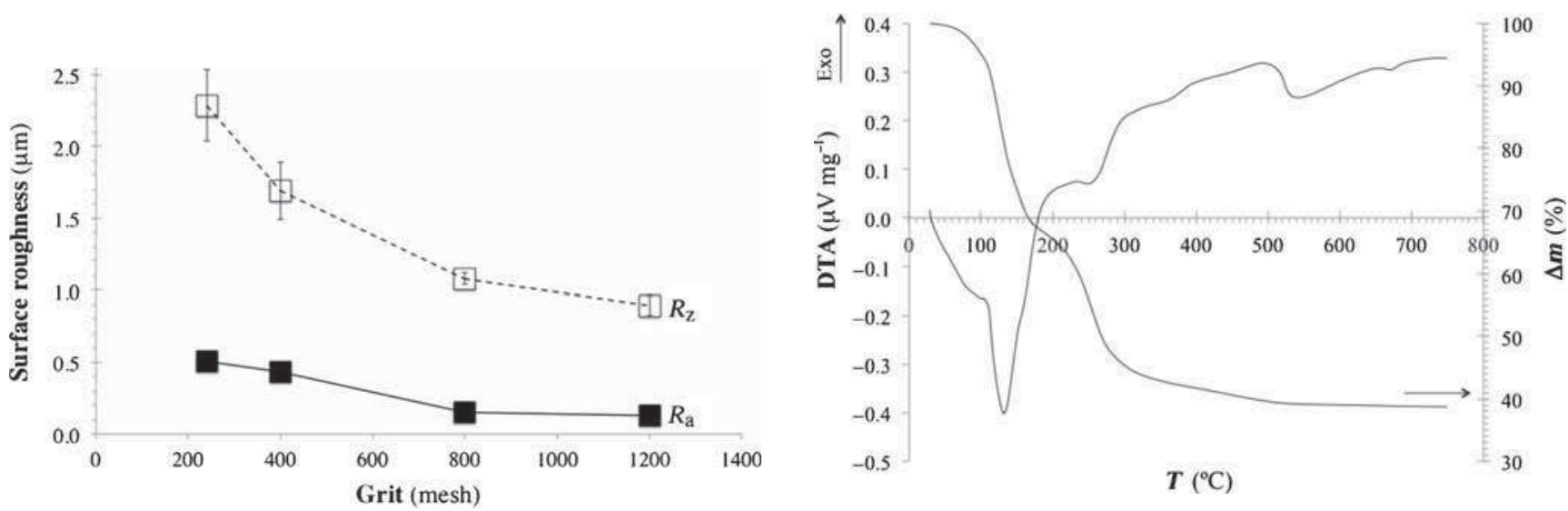

Figure 4. Roughness of grinded Ti surfaces. $R_{\mathrm{a}}$ : average surface roughness $(\mathbf{\square}) ; R_{\mathrm{Z}}$ : surface roughness depth $(\square)$.

loss is attributed to the removal of adsorbed water from the surface and pores of HA, while the second corresponds to the loss of lattice water [9]. The second and third mass losses are combined with small endothermic peaks, likely caused by the removal of other groups in the precursor, such as $-\mathrm{OH}$ and -OEt [9]. Apart from those, the system remains stable during heat treatment above $310^{\circ} \mathrm{C}$.

The HA carrier-gel was easily applied, with good reproducibility. Applied green films were steady and completely covered the underneath Ti surface.

\subsection{Characterization of the sintered coating}

3.3a Coating composition: The sintered gel reveals the presence of all expected major HA peaks (figure 7a), remaining

Figure 6. DTA/TG of as-dried gel (heating at $4^{\circ} \mathrm{C} \min ^{-1}$, under primary vacuum).

crystalline after sintering on the $\mathrm{Ti}$ substrate (figure $7 \mathrm{~b}$ ). A shift of the diffraction peaks corresponding to HA is observed together with a change on their relative intensities, suggesting crystallographic changes. These changes are expected to result from the described events taking place on heating, since the irreversible loss of lattice water (in the $200-400^{\circ} \mathrm{C}$ temperature range) causes a rearrangement of ions to a more stable structure, accompanied by a contraction in the $a$-axis dimensions [14,15]. Peaks corresponding to $\mathrm{TiO}_{2}$ were identified, corresponding to the formation of a thermally grown thin layer of titanium oxide over the metal surface. The $\mathrm{TiO}_{2}$ layer has been shown to be able to subtract $\mathrm{Ca}^{2+}$ ions from the HA film to form an intermediate layer of calcium titanate [7,16]. Accordingly diffraction peaks were detected in the diffractogram in figure $7 \mathrm{~b}$ corresponding to $\mathrm{CaTiO}_{3}$. It is thus suggested that three layers are present over the sintered Ti substrate: thermally grown $\mathrm{TiO}_{2}, \mathrm{CaTiO}_{3}$ interfacial reaction product and HA deposited during coating. The $\mathrm{CaTiO}_{3}$ layer contributes with chemical bonding at 


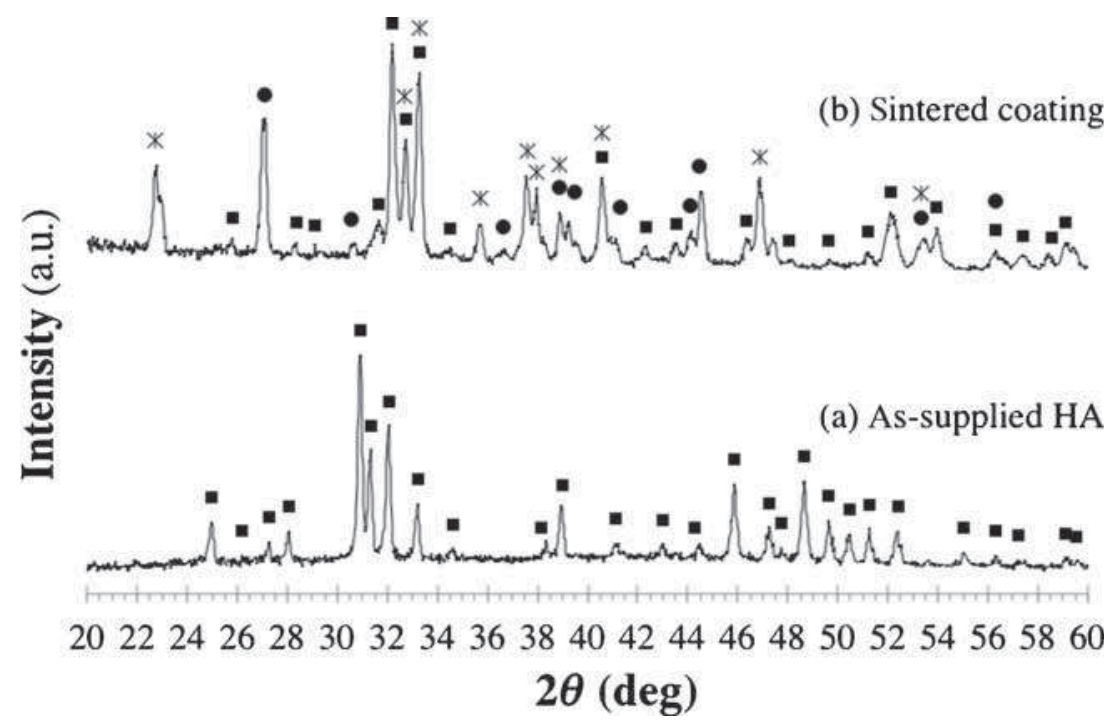

Figure 7. XRD patterns of (a) HA as-supplied powder and (b) coating sintered upon commercially pure titanium (1200 mesh, 5 s). $\left(\mathrm{Ca}_{10}\left(\mathrm{PO}_{4}\right)_{6}(\mathrm{OH})_{2} \square ; \bullet \mathrm{TiO}_{2}\right.$ (rutile); $* \mathrm{CaTiO}_{3}$ ).

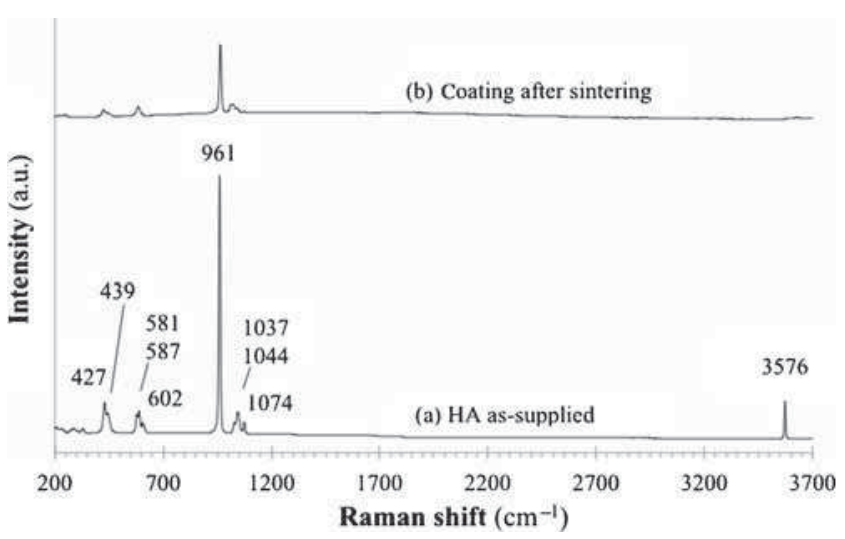

Figure 8. Raman spectra (a) as-supplied HA and (b) surface of the HA coating after primary vacuum sintering at $750^{\circ} \mathrm{C}$ (sample with 1200 mesh substrate finish, $10 \mathrm{~s}$ immersion time).

the substrate/film interface; although bonding at the metalcoating interface is expected to arise mainly from mechanical interlocking, additional adhesion of the HA film to the substrate is expected to result [16]. It should be mentioned that the characteristic peaks of $\mathrm{CaO}, \alpha$ - and $\beta$-tricalcium phosphate and tetracalcium phosphate are absent, stating the crystallographic and chemical purity of the achieved HA layer.

Raman spectra of all HA films deposited on Ti surface are similar, regardless of the imposed surface finish of the metallic surface, and comparable to that of HA (figure 8a). The Raman spectrum of as-supplied HA powder shows a characteristic very strong peak at $961 \mathrm{~cm}^{-1}$, corresponding to the $v_{1}$ domain of the $\mathrm{PO}_{4}$ group ( $\mathrm{P}-\mathrm{O}$ symmetric stretching) [3]. Other bands were assigned to internal vibration modes of phosphate groups: two distinct bands appear at about 427 and $439 \mathrm{~cm}^{-1}$ in the region of the $v_{2} \mathrm{PO}_{4}$ bending mode (doubly degenerate $\mathrm{O}-\mathrm{P}-\mathrm{O}$ bending modes); in the region of the $v_{4} \mathrm{PO}_{4}$ bending mode (triply degenerate $\mathrm{O}-\mathrm{P}-\mathrm{O}$ bending), three peaks appear at 581, 587 and $602 \mathrm{~cm}^{-1}$; in the $v_{3}$ domain three peaks are distinguished at 1037, 1044 and $1074 \mathrm{~cm}^{-1}$ (triply degenerate asymmetric $\mathrm{P}-\mathrm{O}$ stretching). The band at $3576 \mathrm{~cm}^{-1}$ corresponds to the $\mathrm{O}-\mathrm{H}$ stretching in the water functional groups of HA $[5,17,18]$. In good agreement with information by the supplier, the spectral analysis does not show the presence of any calcium phosphate phase other than HA. The spectra collected after sintering of the coating (figure 8b) only differs from that of HA (apart from small wave number shift differences, attributed to laser excitation induced heating of the samples) [3] in the decreased intensity of the $\mathrm{O}-\mathrm{H}$ band at $3576 \mathrm{~cm}^{-1}$, indicating severe water loss. However, the Raman spectra are worse resolved for the sintered films and the corresponding peaks present relatively larger width than pure HA, which is indicative of the existence of structurally disordered phosphate groups [3]. As before, spectral analysis shows the absence of any calcium phosphate phase in the sintered material other than HA.

3.3b Coating morphology: HA films resulting after sintering were uniform at the macroscale, for all $\mathrm{Ti}$ surface roughness and coating times. Coating morphology depends on immersion time and Ti surface roughness (figures 9-11). Surfaces resulting from dipping during 5 and $10 \mathrm{~s}$ present some cracking, with a configuration that suggests differential contraction during sintering (this pattern is also present in all samples produced from Ti with 240 mesh surface finish, including the one resulting from immersion during $1 \mathrm{~s}$ ). Differential contraction is mainly determined by the bonding to the substrate, and is higher with increased coating thickness. Linear contraction is more significant in the throughthickness direction than in in-plane direction, since in this 

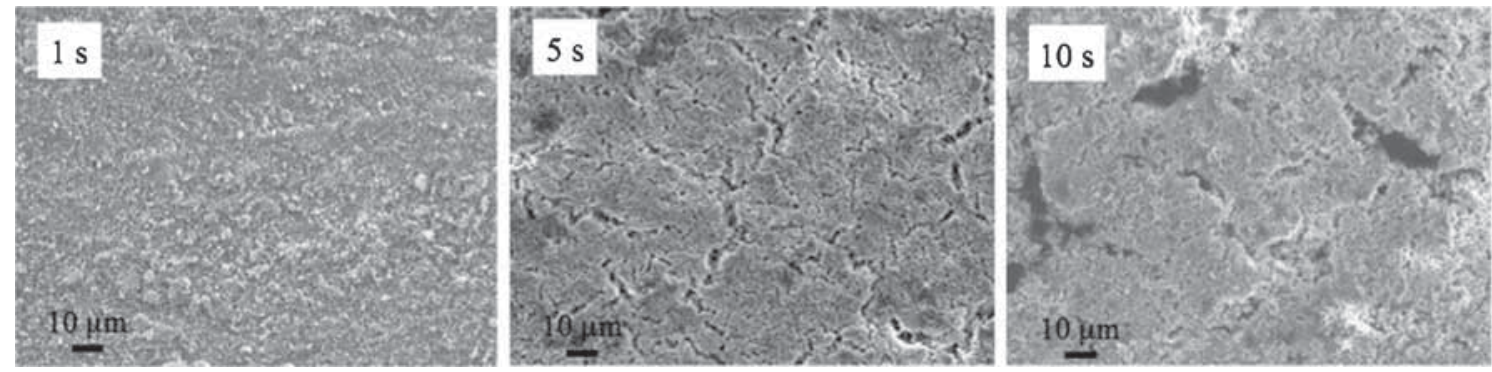

Figure 9. Low-magnification SE image of sintered coatings on Ti strips finished up to 400 mesh after (a) 1 , (b) 5 and (c) $10 \mathrm{~s}$ immersion time (top view).
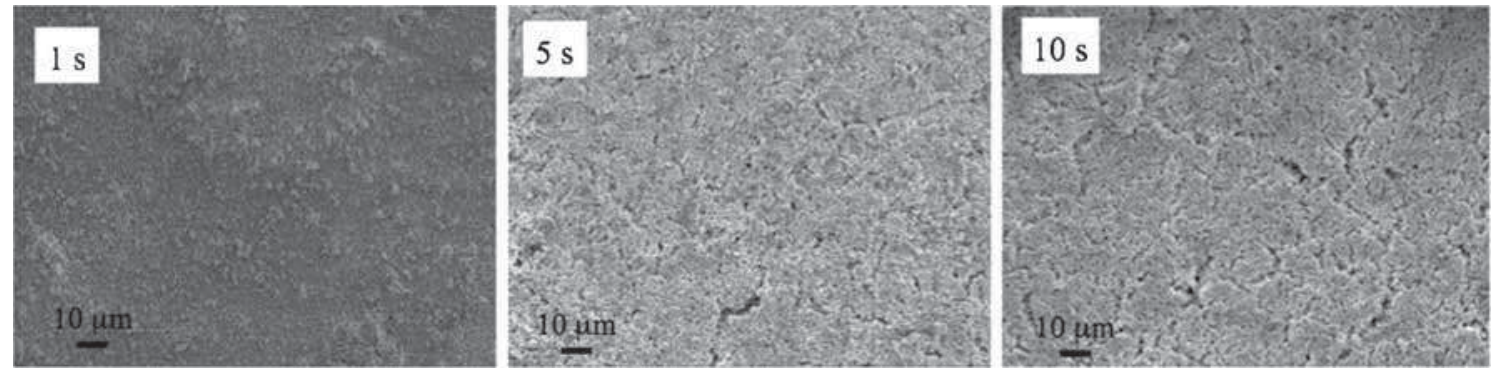

Figure 10. Low-magnification SE image of sintered coatings on Ti strips finished up to 800 mesh after (a) 1 , (b) 5 and (c) $10 \mathrm{~s}$ immersion time (top view).
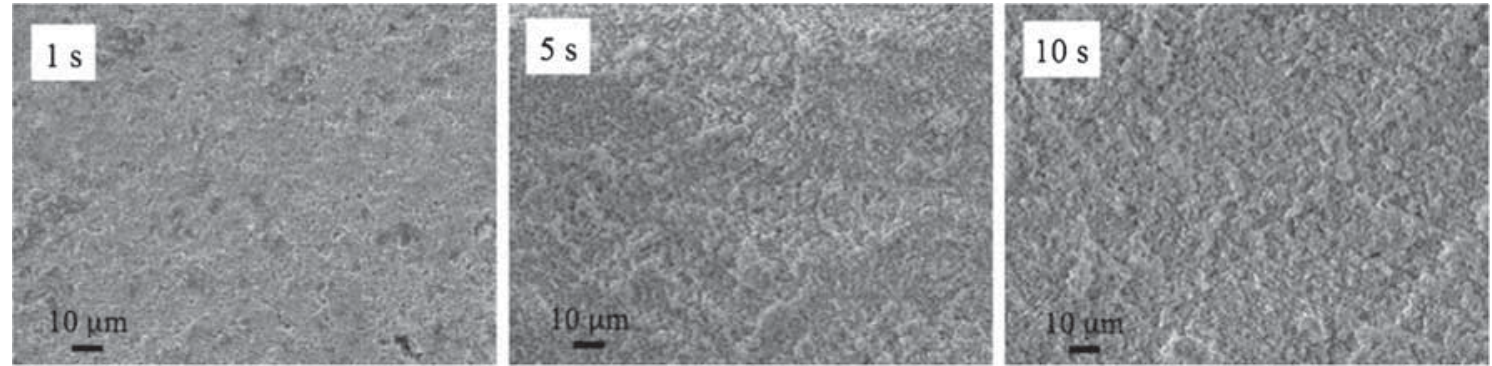

Figure 11. Low-magnification SE of sintered coatings on Ti strips finished up to 1200 mesh after (a) 1 , (b) 5 and (c) $10 \mathrm{~s}$ immersion time (top view).

case sintering is retarded by the presence of tensile stresses resulting from differential thermal expansion between the ceramic coating and the metallic substrate [19]. Sintering is likely to occur much more rapidly near the free surface, not only because temperature is higher, but also because the in-plane stress is compressive in that region, promoting retraction [19]. This constraint is more significant for thicker coatings, resulting in higher crack density. Additionally, the formation of $\mathrm{CaTiO}_{3}$ indicates strong bonding to the substrate and thus build up of residual stresses in the film during sintering. Greater residual stresses arise in the thicker films, resulting in increased cracking frequency.

Attained film thickness varies from a minimum of $22.0 \mu \mathrm{m}$ for samples with 1200 mesh surface finish dipped during $1 \mathrm{~s}$, to a maximum of $47.5 \mu \mathrm{m}$ for samples with 240 mesh surface finish dipped during $10 \mathrm{~s}$ (figure 12). Increased film thickness results from increasing dip-coating times. The measured film

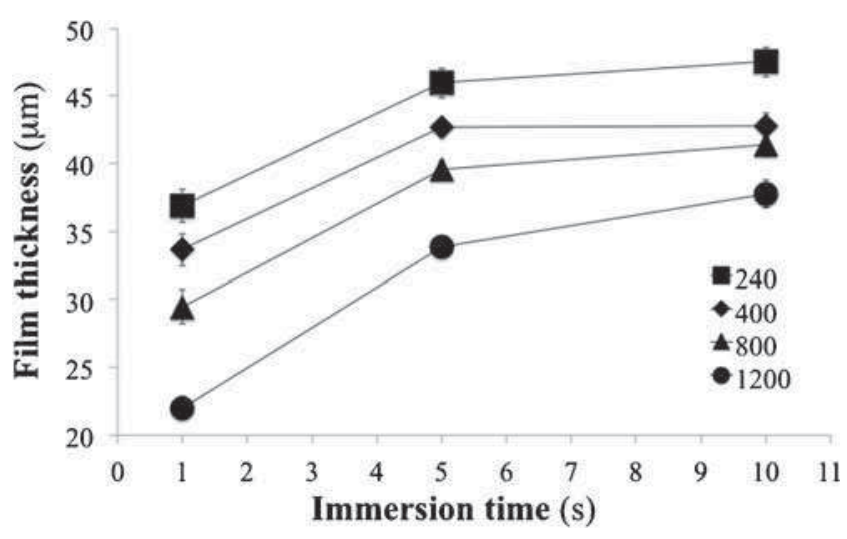

Figure 12. Film thickness of sintered HA coating upon Ti strips resulting from different immersion times as a function of surface finish. 
height is approximately constant through the whole surface, indicating that film thickness is uniform. Film thickness is higher for substrate surfaces with higher surface roughness, and for every substrate surface finish film thickness increases with the increase in dipping time.

Figures 9-11 suggest that liquid phase sintering was not achieved, despite the addition of $\mathrm{KH}_{2} \mathrm{PO}_{4}$, which has been reported as sintering flux [10]. Low-temperature solid-state sintering resulted in overall low densification and high porosity in all studied systems. The bulk density of sintered HA layers was calculated by weight measurement before coating and after sintering (weight variation was assigned to the deposited layer), and coating thickness (figure 12). Attained results are reported in figure 13 as a percentage of HA theoretical density $\left(3.16 \mathrm{~g} \mathrm{~cm}^{-1}\right)$ [20]. Coating density varies from $42 \% \mathrm{TD}$ (58\% porosity) in samples with 1200 surface finish dipped during $1 \mathrm{~s}$ to $74 \% \mathrm{TD}$ ( $26 \%$ porosity) in samples with 240 surface finish dipped during $10 \mathrm{~s}$.

The produced coatings present average surface roughness between $0.94 \mu \mathrm{m}$ (1200 mesh, $10 \mathrm{~s})$ and $1.94 \mu \mathrm{m}$ (240 mesh, $1 \mathrm{~s}$ ) (figure 14). Within the same metal surface preparation, both coating porosity (figure 13) and coating roughness decrease with the increase in immersion time. This is expected to result from the fact that for short immersion times the films do not completely fill the valleys in the grinded substrate, but rather follow its profile [16]. With increasing immersion time the increase of solution deposited during dip coating allows peak-and-valley smoothing and the decrease of surface roughness. These results are in good agreement with other authors, which state that a smoother surface of substrate generates a more uniform thickness of the HA layer during drying and sintering [5]. Rougher substrate surfaces can be bonded to a higher HA volume, causing increased cracking as a result of differential shrinkage during drying and sintering. The lower the surface roughness, the higher uniformity and the fewer cracks can be obtained, in good agreement with surface morphology as displayed in figures $8-10$. Smoother substrate surfaces also cause less thermal stress. The surface roughness of the substrate is particularly important in HA coating because it can provide increased coating/substrate mechanical interlocking, thus reducing the failure probability of the coated layer [5].

3.3c Evaluation of mechanical properties: The mechanical behaviour of the produced HA coatings was evaluated by hardness test and from damage tolerance to scratch test. Hardness (figure 15) increases with substrate surface roughness and with immersion time, varying between a minimum value of HV $148 \pm 14$ (i.e., approximately $29 \%$ of the typical hardness value of fully dense HA) [20] for 1200 surface finish immersed during $1 \mathrm{~s}$, and a maximum of $\mathrm{HV}$ $232 \pm 9$ (approximately $45 \%$ of the hardness value of fully dense HA). The lower hardness values are attained for an immersion time of $1 \mathrm{~s}$, for all Ti surface finish. Attained values are quite lower than bulk HA (HV 510) [20] and higher

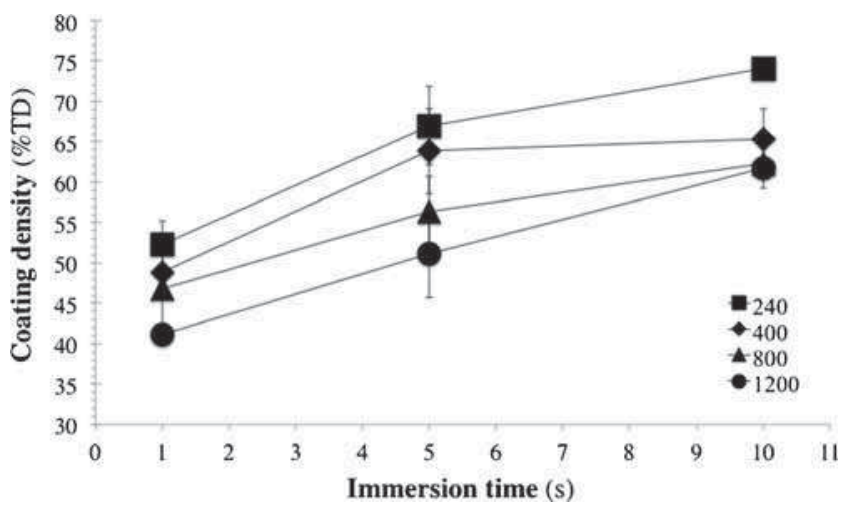

Figure 13. Applied coating density as a function of immersion time and surface finish.

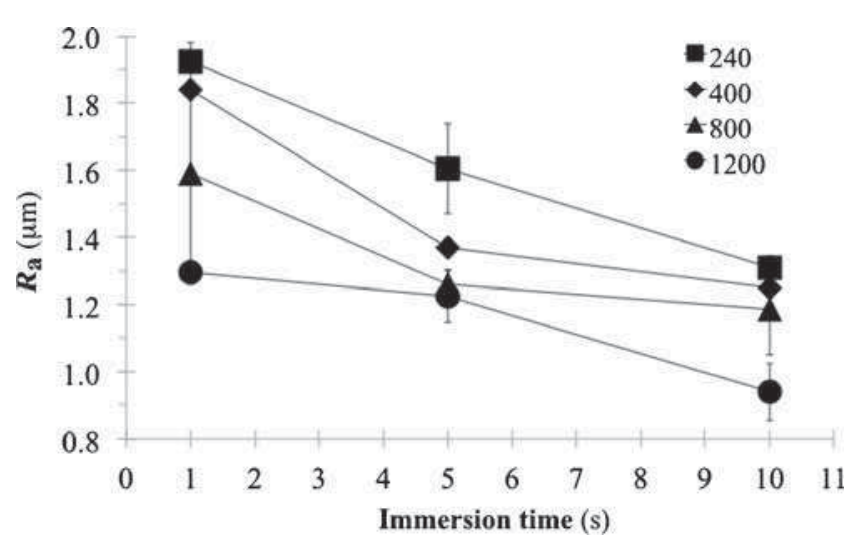

Figure 14. Average roughness of HA surfaces as a function of time and substrate surface finish.

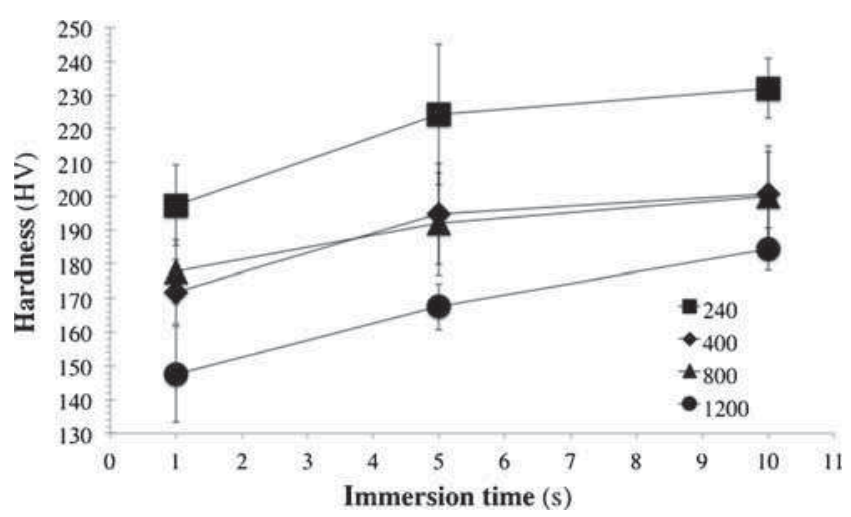

Figure 15. Surface hardness as a function of coating time and $\mathrm{Ti}$ substrate surface finish.

than commercially pure titanium (HV 114) [11]. High coating porosity resulting from poor densification of the HA film is presumably the cause for the low attained hardness values (the presence of porosity is however expected to be quite beneficial for mechanical interlocking during osteoconduction). 

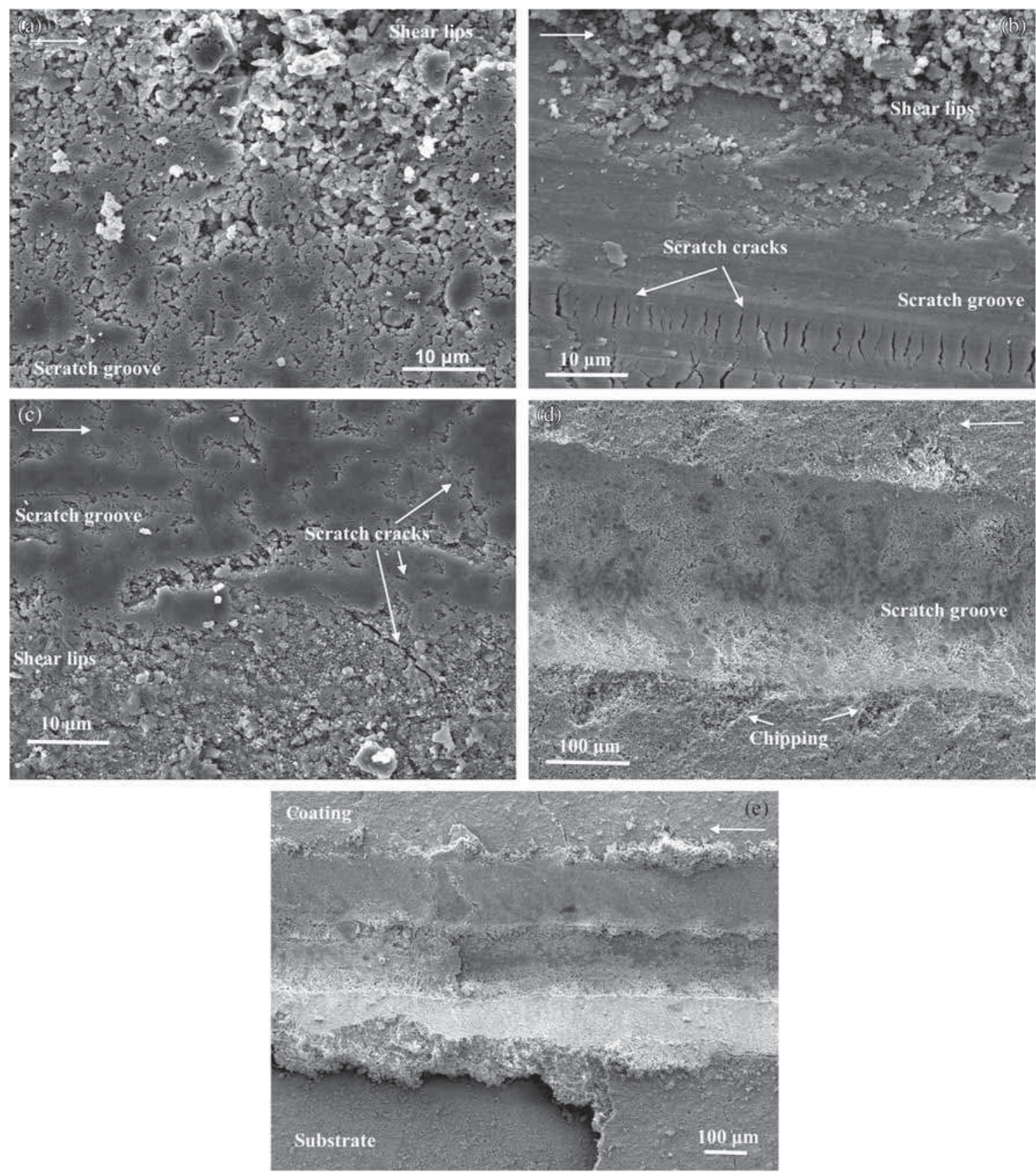

Figure 16. SEM images of the groove formed after scratch test, exemplifying the detected scratch types: (a) type I (sample with 240 surface finish immersed during $1 \mathrm{~s}, 1 \mathrm{kgf}$ applied load); (b) type II (800 mesh, $5 \mathrm{~s}, 4 \mathrm{kgf}$ ); (c) type III (1200 mesh, $5 \mathrm{~s}, 2 \mathrm{kgf}$ ); (d) type III with chipping (240 mesh, $10 \mathrm{~s}, 1 \mathrm{kgf}$ ); and (e) type IV (400 mesh, $1 \mathrm{~s}, 4 \mathrm{kgf}$ ) (horizontal arrows denote the sliding direction).

Additionally film thickness is higher for samples with higher substrate surface roughness (figure 12), suggesting that the low hardness of commercially pure Ti contributes to the relatively low hardness values of the coatings with smoother substrate.

Adhesion and toughness features of the coatings were assessed by scratch test; the response depends on applied load and varies with substrate surface finishing and immersion time. Scratch test of the produced HA-coated titanium composites resulted in the following modes of response (exemplified in figure 16), with damage severity increasing through the sequence I-IV [21]:

I. Plastically formed groove with shear lips development, without associated cracks (figure 16a).

II. Plastically formed groove with shear lips development. Both straight and semi-circular cracks develop in the groove, opened to the direction of scratching and oriented normal to scratching direction (figure 16b). 
Table 1. Scratch mode map for HA-coated titanium showing behaviour zones for the tested scratch loads.

\begin{tabular}{|c|c|c|c|c|c|c|c|c|c|c|c|c|}
\hline \multirow[b]{4}{*}{ Test load (kgf) } & \multicolumn{12}{|c|}{ Surface finish (mesh) } \\
\hline & \multicolumn{3}{|c|}{240} & \multicolumn{3}{|c|}{400} & \multicolumn{3}{|c|}{800} & \multicolumn{3}{|c|}{1200} \\
\hline & \multicolumn{12}{|c|}{ Coating time (s) } \\
\hline & 1 & 5 & 10 & 1 & 5 & 10 & 1 & 5 & 10 & 1 & 5 & 10 \\
\hline 1 & I & I & III & I & I & I & I & I & $\mathrm{I}$ & II & II & III \\
\hline 2 & IV & II & IV & II & I & II & II & I & IV & II & III & IV \\
\hline 4 & IV & IV & IV & IV & IV & IV & II & II & IV & IV & IV & IV \\
\hline
\end{tabular}

Damage severity is classified from I to IV, according to text above. Grey level of cells indicates severity of damage resulting from scratch test: from mode I (no crack formation) — light grey, to mode IV (severe spallation) — black with white lettering.

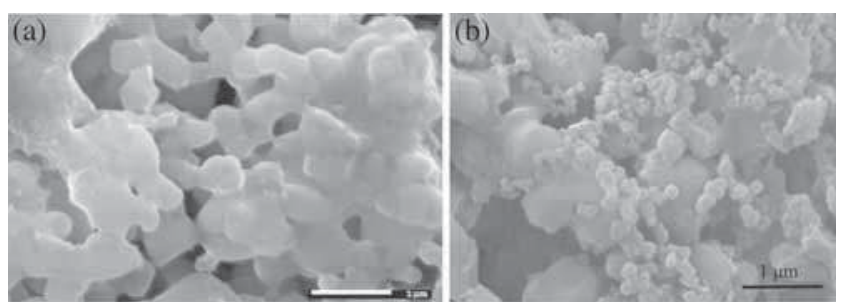

Figure 17. Surface of dip-coated sample (800 mesh, $10 \mathrm{~s})$ : (a) before immersion in SBF and (b) after thermostatic immersion in SBF during 4 weeks.

III. Plastically formed groove, without shear lips development. Cracks develop in the groove such as in III but propagate to adjacent material (figure 16c). Eventually the coating is detached, leading to slight chipping at the groove side (figure 16d). This failure mode results from crack propagation outside the scratch before the indenter passes over it; once the indenter reaches the region it causes a chip to be removed [22].

IV. Plastically formed groove with gross spallation in shear lips and adjacent areas, with coating failure and removal (figure 16e). Large area spallation is common if coating/substrate adhesion is poor or if the residual stress level in the coating is high [22]. In either case, as the indenter contacts the coating, a crack is formed at the coating/substrate interface which can propagate a considerable distance either side of the groove.

The response of the produced coatings to scratch test varies according to substrate finishing, coating thickness and applied load: table 1 summarizes attained results showing relevant transitions in coatings scratch mode behaviour. Low damage behaviour (response mode I) is generally observed for scratch tests carried out with an applied load of $1 \mathrm{kgf}$. However, under an applied load of $4 \mathrm{kgf}$ most coatings show cracking and severe spallation (mode IV). Tests carried out with a $2 \mathrm{kgf}$ load allow a better insight in the toughness and adhesion of the coatings: these suggest that HA coatings produced on Ti substrates with a surface finish of 400 and particularly 800 mesh (respectively, $R_{\mathrm{z}}=1.69 \mu \mathrm{m}, R_{\mathrm{a}}=$ $0.44 \mu \mathrm{m}$ and $R_{\mathrm{z}}=1.08 \mu \mathrm{m}, R_{\mathrm{a}}=0.15 \mu \mathrm{m}$ ), having a thickness of $\sim 30-40 \mu \mathrm{m}$ and $45-50 \%$ HA theoretical density are the toughest coatings produced by the proposed dip-coating method. These coatings thus display an attractive combination of toughness and sufficiently high hardness (figure 15). In most of the produced coatings decohesion does not take place under a test load of $1 \mathrm{kgf}$, stating adequate interfacial bonding. The exception are those applied on the 1200 mesh surface finish substrate (feasibly because of low coating/substrate mechanical interlocking), and those resulting from dipping a 240 mesh finish strip during $10 \mathrm{~s}$ (as coating thickness increases cracking and chipping along the scratch edges becomes more likely) [22]. On the other hand some coatings (with exception of the discussed HA coatings with 400 and 800 mesh substrate finish) show coating/substrate decohesion above $2 \mathrm{kgf}$, and most of them fail above $4 \mathrm{kgf}$. These responses to scratch test suggest boundaries for the critical load of each tested composite: the 400 and 800 mesh substrate finish samples dipped in the HA-carrier gel during $5 \mathrm{~s}$ are expected to show the first signs of adhesive failure above an applied load of $2 \mathrm{kgf}$, while in coatings with 240 (dipped during $10 \mathrm{~s}$ ) and 1200 mesh substrate surface finish failure begins bellow $1 \mathrm{kgf}$. All other produced coatings are expected to fail between 1 and $2 \mathrm{kgf}$ applied load.

3.3d Evaluation of apatite forming ability: As a consequence of sample exposure to simulated body fluid, it was found that ion deposition leading to formation of apatite (i.e., mainly $\mathrm{Ca}$ and $\mathrm{P}$ ) takes place. After thermostatic immersion in SBF during 4 weeks there is significant difference between the samples surface microstructure (figure 17). EDS elemental analysis showed that the deposited particles (figure $17 \mathrm{~b})$ are rich in calcium and phosphorous $(\mathrm{Ca} / \mathrm{P}$ molar ratio $\sim 1.62$ ), attesting that the produced composites retain the ability of the starting materials to induce heterogeneous nucleation of HA deposits. The ability to form apatite on the material surface has been suggested to correlate to its ability to bond to living bone in the living host through that layer [12].

\section{Conclusion}

In this work HA films were deposited upon titanium substrate using straightforward and inexpensive dip-coating technology. Contamination of HA or formation of deficient HA 
during synthesis simultaneous to coating was bypassed by using commercial HA particles conveyed on a gel. The constancy of HA chemical and crystallographic nature was thus assured during the coating operation.

Attained results indicate that high-quality bioactive HA coatings on commercially pure titanium substrate can be produced at a firing temperature as low as $750^{\circ} \mathrm{C}$, using the dip-coating technique into a HA-carrier gel. The metallic substrate surface preparation (surface roughness) and the immersion time in the prepared HA gel significantly affect the structure and properties of the HA coating layer after sintering: higher substrate surface roughness and longer immersion time produce thicker, denser films, with higher surface roughness. Lower film porosity is accompanied by higher hardness values. However, thicker coating promotes differential shrinkage and crack formation during sintering. Thicker coatings present lower damage tolerance, while smoother surface finish of the metallic substrate results in low coating/substrate mechanical interlocking and lower adhesion. HA coatings with 45-50\% HA theoretical density produced on Ti substrates with $R_{\mathrm{Z}}$ surface roughness of $1.0-1.7 \mu \mathrm{m}$, and thickness of $\sim 30-40 \mu \mathrm{m}$ display an attractive combination of high hardness and toughness. Within the tested coating conditions the most promising results are obtained when the titanium substrate is finished to 400 or 800 mesh and dipped in the HA-carrier gel during $5 \mathrm{~s}$.

Overall, although this process is reliable, fast, economical and scalable, the most adequate processing parameters are dedicated and must be determined for each application, especially when intricate geometries are to be coated.

\section{References}

[1] Kalita S J, Bose S, Hosick H L and Bandyopadhyay A 2004 Biomaterials 252331
[2] Sadat-Shojai M, Khorasani M-T, Dinpanah-Khoshdargi E and Jamshidi A 2013 Acta Biomater. 97591

[3] Koutsopoulos S 2002 J. Biomed. Mater. Res. 62600

[4] Xiao X F and Liu R F 2006 Mater. Lett. 602627

[5] You C, Oh S and Kim S 2001 J. Sol-Gel Technol. 2149

[6] Ü̈ N S 2008 Development of sol-gel derived hydroxyapatite-titania coatings. Master thesis, Middlle East University, Turkey

[7] Huaxia J I, Ponton C B and Marquis P M 1992 J. Mater. Sci. Mater. Med. 3283

[8] Demnati I et al 2012 Surf. Coat. Technol. 2062346

[9] Kim I-S and Kumta P N 2004 Mater. Sci. Eng. B 111232

[10] Aksakal B and Hanyaloglu C 2008 J. Mater. Sci. Mater. Med. 192097

[11] Lampman S 1990 ASM Handbook, Vol 2 - Properties and selection: nonferrous alloys and special-purpose materials (ASM International) p 592

[12] Kokubo T and Takadama H 2006 Biomaterials 272907

[13] Hardcastle F D, Ishihara H, Sharma R and Biris A S $2011 \mathrm{~J}$. Mater. Chem. 216337

[14] LeGeros R Z, Bonel G and LeGeros R 1978 Calcif. Tissue Res. 26111

[15] Liao C-J, Lin F-H, Chen K-S and Sun J-S 1999 Biomaterials 201807

[16] Montenero A, Gnappi G, Ferrari F, Cesari M and Salvioli E 2000 J. Mater. Sci. 52791

[17] de Aza P N et al 1997 Chem. Mater. 9916

[18] Huang J, Best S M, Bonfield W and Buckland T 2010 Acta Biomater. 6241

[19] Tsipas S A, Golosnoy I O, Damani R and Clyne T W 2004 J. Therm. Spray Technol. 13370

[20] Orlovskii V P, Komlev V S and Barinov S M 2002 Inorg. Mater. 38973

[21] Hutchings I M 1992 Tribology: friction and wear of engineering materials (Boca Raton: Edward Arnold)

[22] Bull S J 1991 Surf. Coat. Technol. 5025 